\title{
GM Research Labs Host AIP Corporate Associates OSTP Director Bromley Speaks
}

The annual meeting of the American Institute of Physics Corporate Associates convened in early October at the General Motors Research Laboratories just outside of Detroit, Michigan. The first of two days was devoted to the theme of "Creating New Materials: Physics with an Economic Perspective."

Numerous technical presentations, some formal and others from selected research laboratories, highlighted a wide range of primarily materials research areas of interest to General Motors. Examples of successful in-house development of discoveries into economic fruition were featured in talks by Jan Herbst on the rare-earth-iron-boron magnet materials and by Gary Tibbetts on graphite fibers from natural gas. Other members of the GM Laboratories' staff reported on such ongoing research activities as polymer/ liquid crystal films, diamond films, compound semiconductors, high temperature superconductors, and surface chemistry for catalytic reactions.

The second day of the meeting focused mainly on issues of science and technology policy. The keynote speaker was D. Allan Bromley, who has a dual role as the Assistant to the President for Science and Technology and as the newly confirmed director of the Office of Science and Technology Policy (OSTP).

Bromley defined his OSTP responsibilities as twofold-to provide the best technical information and evaluation [his emphasis] to the administration for decisions on current scientific issues, and to establish a wide ranging policy for the support of science and technology within the United States. To help address these missions he is strongly encouraging President Bush to appoint four associate directors of OSTP. These positions were authorized in the 1976 law that created OSTP but have yet to be filled. The names of candidates for two of these associates, for Life Sciences and for Policy and International Affairs, have been submitted to Congress for confirmation. The other two names, for Physical Sciences and Engineering and for Industrial Technology, will likely be submitted within six weeks.

To consolidate the ideas and considerations of the many federal agencies and U.S. industries, Bromley advocated the creation of a President's Council of Advisers on Science and Technology (PCAST), which would meet periodically in the White House. PCAST would consist of representatives from government and nongovernmental science and technology communities, and would function both as an advisory and a coordinating committee.

Bromley discussed several specific areas of immediate concern. Global environmental issues such as acid precipitation, stratospheric ozone, planetary warming, and air pollution "are at the top of the agendas of all major nations in the West," he said. Working with the science ministers of these countries Bromley hopes to obtain international consensus and action to alleviate these problems. Energy is closely linked with many of these as it is with other U.S. concerns. Bromley feels that the U.S. must begin again to look at alternate energy sources.

The agenda of "mega-projects" proposed for the United States, he said, is simply too much to support simultaneously, and a priority list must be made. With the Superconducting Supercollider already under way, the remaining agenda items still include Mission to Planet Earth, space stations, more planetary expeditions, and human genome sequencing. Bromley implied that international collaboration on these projects will be sought, and that the support will be documented by "treaties" as guarantees of lasting participation. $\mathrm{He}$ was also careful to state that he will work "to prevent mega-projects from destroying small science."

Materials science is receiving Bromley's special attention. He referred several times to the recently released National Research Council (NRC) study report on materials science and engineering, which was the output from a multiple-year study chaired by $\mathrm{P}$. Chaudhari and M. Flemings. (Editor's Note: For a synopsis of the MS\&E study report and comments offered during its unveiling at the Solid State Sciences Committee forum, see p. 27-32 in the October 1989 MRS BULLETIN.)

Although we have truly reached the age of tailored materials, said Bromley, this study report documents a "major gap in synthesis and production" within the United States. To directly address this deficiency and more generally establish a national policy on materials science and engineering, Bromley proposed appointing a focused committee under PCAST. Reflecting the structure of PCAST, this

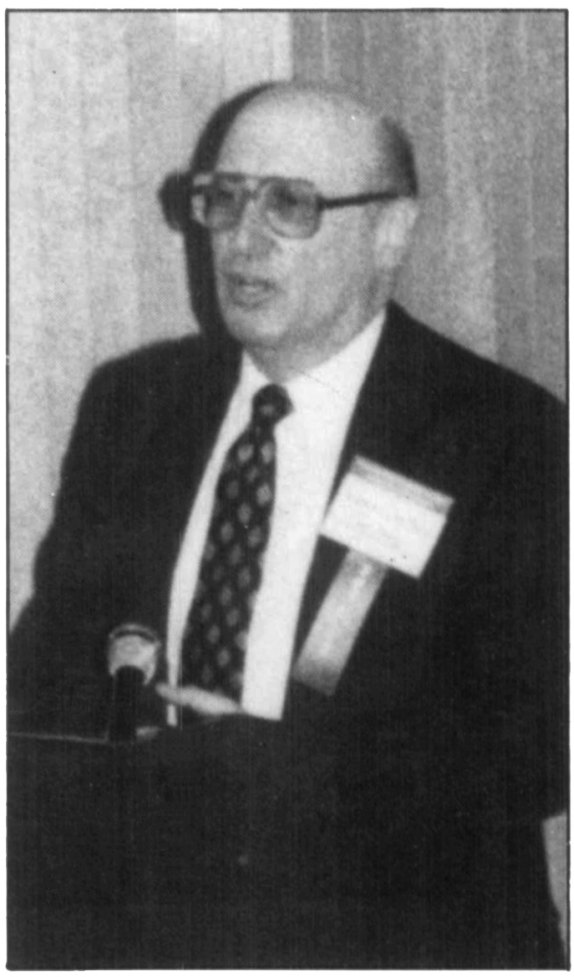

OSTP Director D. Allan Bromley delivers keynote address at AIP Corporate Associates meeting.

committee would be composed of government and nongovernment representatives and would use the study report as the basis for its actions.

Underlying many aspects of science and technology within the United States, including public policy, national security, and economic competitiveness, is the low, and not increasing, level of technical education and training. This must improve for the United States to be informed and effective, said Bromley. He is convinced that the Bush administration will act on the crucial science education issues, but emphasized the need for a national commitment from practicing scientists and engineers to assist the process.

As a parting comment, Bromley noted the "need for constituencies in the various sciences to compete effectively for federal funds."

Gordon E. Pike Sandia National Laboratories 